\title{
Caracterização de larvas de trematódeos emergentes de moluscos gastrópodes coletados em Mariana, Minas Gerais, Brasil
}

\author{
Marco A. A. Souza ${ }^{1} \&$ Alan L. Melo ${ }^{2}$ \\ 1. Laboratório de Análises Clínicas, Departamento de Ciências da Saúde, Centro Universitário Norte do Espírito Santo, Universidade Federal do Espírito Santo. Rodovia BR 101 Norte, km 60 , \\ Bairro Litorâneo, 29932-540, São Mateus, ES. (marcosouza@ceunes.ufes.br) \\ 2. Laboratório de Taxonomia e Biologia de Invertebrados, Departamento de Parasitologia, Instituto de Ciências Biológicas, Universidade Federal de Minas Gerais. Avenida Antônio Carlos, \\ 6627, Pampulha, Caixa Postal 486, 30123-970, Belo Horizonte, MG. (aldemelo@icb.ufmg.br)
}

\begin{abstract}
Characterization of larval trematodes emerging from gastropod mollusks collected in Mariana, Minas Gerais, Brazil. In malacological survey conducted at Mariana municipality, state of Minas Gerais, Brazil, between April 2003 and February 2004 were found Biomphalaria glabrata (Say, 1818) and Physa marmorata Guilding, 1828 mollusks harboring Digenea larval trematodes. In B. glabrata were observed, in addition to cercaria of Schistosoma mansoni Sambon, 1907, strigeocercaria, two types of xiphidiocercaria, ocellifera cercaria and two types of gymnocephalus, while in P. marmorata the only larval form emerging was echinostome cercaria. Some of cercariae found differ from those described in the literature.
\end{abstract}

KEYWORDS. Malacological survey, cercaria, morphology.

RESUMO. Em levantamento malacológico realizado no município de Mariana, estado de Minas Gerais, Brasil, entre abril de 2003 e fevereiro de 2004 foram encontrados moluscos Biomphalaria glabrata (Say, 1818) e Physa marmorata Guilding, 1828 albergando larvas de trematódeos digenéticos. Em B. glabrata foram observadas além de cercária de Schistosoma mansoni Sambon, 1907, estrigeocercária, dois tipos de xifidiocercária, cercária ocelífera e dois tipos de gimnocéfala, enquanto em P. marmorata a única forma larvar emergente foi a cercária equinóstoma. Algumas das cercárias encontradas diferem daquelas descritas na literatura.

PALAVRAS-CHAVE. Levantamento malacológico, cercária, morfologia.

Várias formas larvares de trematódeos oriundas das mais diversas espécies de hospedeiros intermediários no Brasil foram descritas e caracterizadas por diferentes autores desde o início do século passado (LuTZ, 1917, 1919, 1922, 1924, 1931, 1933, 1934; Moura, 1945; Ruiz, 1943, 1952a,b,c,d, 1953, 1957), porém o conhecimento do ciclo biológico completo e o impacto das infecções em populações de moluscos por essas larvas ainda é pouco conhecido, tendo em vista que muitas formas larvares, quando do exame laboratorial, são negligenciadas, enquanto outras apresentam morfologia que à primeira observação podem levar a confusão com Cercaria blanchardi Pirajá da Silva, 1912, forma larvar de Schistosoma mansoni Sambon, 1907.

Lutz, um dos pioneiros nos estudos de infecção em moluscos límnicos por outras larvas de trematódeos, descreveu uma larva encontrada em Biomphalaria tenagophila (d'Orbigny, 1835), denominando-a de Cercaria ocellifera (LuTz, 1917). Posteriormente, ao estudar o desenvolvimento do parasito, concluiu ser a larva de Clinostomum heluans Braun, 1899 (LuTz, 1917, 1934). Alguns anos mais tarde este tipo de larva foi registrado nos estados de São Paulo (Moura, 1945) e Rio de Janeiro (PARAense, 1951). Ruiz (1953) redescreveu a mesma larva fornecendo as medidas e completando a caracterização da espécie.

RuIz (1952b) ao observar exemplares de Biomphalaria glabrata (Say, 1818) provenientes de São Paulo, verificou a presença de larvas de $S$. mansoni, redescreveu a larva (Cercaria granulifera) de Paryphostomum segregatum Dietz 1909 e Cercaria lutzi Ruz (1943). Em 1952, caracterizou C. hemiura e
C. santense (Ruzz, 1952b). De B. tenagophila, oriunda de Santos, descreveu C. amplicoecata (RuIZ, 1953). Alguns anos após, ainda em São Paulo, o mesmo autor relatou B. tenagophila parasitada por xifidiocercárias, equinostomocercárias e cistocercárias e ainda Drepanotrema lucidum (Pfeiffer,1839) $(=D$. melleum (LuTZ, 1918)) parasitado por xifidiocercárias (RuIZ, 1957).

Em Minas Gerais, ao estudar as cercárias oriundas de moluscos coletados em Belo Horizonte e Jaboticatubas, de vários tipos larvares diferentes encontrados, Ruiz (1952c) descreveu C. acaudata, $C$. macrogranulosa e $C$. minense e em 1953, descreveu $C$. caratinguensis, de moluscos coletados no município de Caratinga (Ruzz, 1953).

Após esse período, outros registros de moluscos límnicos parasitados por larvas de trematódeos voltaram a ocorrer a partir dos anos 1980. Entre eles destacamse Veitenheimer-Mendes (1981, 1982), VeitenheimerMendes \& Almeida-Caon (1989) e VeitenheimerMeNDEs et al. (1995), que observaram e caracterizaram furcocercárias, equinostomocercárias e xifidiocercárias oriundas de B. tenagophila, B. peregrina (d'Orbigny, $1835)$ e $D$. kermatoides (d'Orbigny, 1835) no Rio Grande do Sul; Melo \& Pereira (1985) que observaram em Minas Gerais B. tenagophila infectada por $S$. mansoni, além de xifidiocercárias; MACHADO et al. (1987) que ilustraram algumas formas larvares (furcocercárias, equinostomocercária e xifidiocercárias) oriundas de $B$. tenagophila do interior de São Paulo; Espíndola et al. (1992), que em Santa Catarina encontraram em D. cimex (Moricand, 1839) e B. tenagophila, estrigeocercárias (C. caratinguensis), equinostomocercárias (C. macrogranulosa) e ocelíferas e 
SouzA et al. (1998), que após o levantamento malacológico da microrregião de Belo Horizonte observaram em $B$. glabrata, B. tenagophila, B. straminea (Dunker, 1848) e Physa marmorata Guilding, 1828, os seguintes tipos larvais: C. macrogranulosa, C. caratinguensis, $C$. minense, $C$. hemiura, $C$. ocellifera e $C$. blanchardi.

Thiengo et al. (1998, 2001), Boaventura et al. (2002), BogÉa et al. (2005) e Pinto \& Melo (2010a, b), em estudos malacológicos realizados na região metropolitana do estado do Rio de Janeiro e na Lagoa da Pampulha, em Belo Horizonte relataram o encontro de diferentes tipos de larvas de trematódeos (equinostomocercárias, estrigeocercárias, xifidiocercárias, cercárias megalura parapleurolophocerca e pleurolophocerca) em $B$. tenagophila, Gundlachia ticaga (Marcus \& Marcus, 1962), P. marmorata, Drepanotrema pfeifferi (Strobel,1874) (=Antillorbis nordestensis (Lucena, 1954)), D. cimex, Melanoides tuberculata (Müller, 1774), Heleobia davisi Silva \& Tomé, 1985 e Lymnaea columella Say, 1817. Nesse contexto, destaca-se o primeiro relato para o Rio de Janeiro e Brasil de M. tuberculata albergando cercárias pleurolophocerca (THIENGo et al., 2001). Outros estudos como os de Carvalho et al. (2001a,b) verificaram xifidiocercárias em moluscos de São Paulo e DiAs et al. (2002), que ao examinar várias espécies de moluscos oriundos do Paraná, observaram cercárias de cauda bifurcada (Diplostomidae e Strigeidae além de Apharyngostrigea sp.) em B. peregrina. Recentemente, em artigo de revisão, Pinto \& Melo (2011) apresentaram lista de várias espécies de trematódeos transmitidas por M. tuberculata. De acordo com os autores, o tiarídeo foi relatado como hospedeiro intermediário de trematódeos pertencentes a 17 famílias, 25 gêneros e 37 espécies, além de várias espécies de Cercaria descritas de $M$. tuberculata, porém ainda não associadas aos respectivos parasitos adultos.

Tendo em vista que os estudos de caracterização de larvas de trematódeos digenéticos podem contribuir com um possível controle biológico de parasitos de importância médica e veterinária, objetiva-se descrever cercárias emergidas de gastrópodes límnicos coletados no Município de Mariana, Minas Gerais.

\section{MATERIAL E MÉTODOS}

O município de Mariana está localizado na região central do estado de Minas Gerais, $\left(20^{\circ} 08^{\prime} 00^{\prime \prime}\right.$ $\left.20^{\circ} 35^{\prime} 00^{\prime \prime} \mathrm{S}, 43^{\circ} 05^{\prime} 00^{\prime \prime}-43^{\circ} 30^{\prime} 00^{\prime} \mathrm{W}\right)$, distante cerca de $110 \mathrm{~km}$ de Belo Horizonte, capital do estado. Em sua divisão territorial apresenta nove distritos, mais a sede da cidade (Fig. 1). Limita-se com os municípios de Catas Altas e Alvinópolis a norte, Barra Longa e Acaiaca a leste, Ouro Preto a oeste e Piranga e Diogo de Vasconcelos a sul (IBGE, 2000).

De acordo com a classificação de Köppen (Strahler, 1963), são descritos dois tipos climáticos para o município: (1) Cwb, que predomina nos locais menos elevados, compreendendo um clima úmido com verão quente, estação seca curta e temperatura média anual entre 19,5 e $21,8^{\circ} \mathrm{C}$ e (2) $\mathrm{Cwb}$, predominante nas porções mais elevadas, caracterizado pelo verão mais brando e temperatura média anual mais baixa $(17,4$ a $19,8^{\circ} \mathrm{C}$ ). Os meses de dezembro, janeiro e fevereiro são os que registram as maiores precipitações, sendo o índice médio pluviométrico anual de $1.800 \mathrm{~mm}$ (CPRM, 1993).

Nesta área de estudo foram verificadas as coleções hídricas, levando-se em consideração, para a escolha dos pontos de captura, a presença humana e de coleções aquáticas, estas, com alterações antrópicas ou não, ou sujeitas a elas.

Os sistemas lóticos e lênticos em diferentes níveis de utilização e conservação que possam representar a variabilidade ecológica dentro das bacias que compõem o município foram determinados. Entre os ambientes lóticos, aqueles constituídos por coleções de água corrente, destacaram-se os córregos, as cachoeiras e os rios e entre os ambientes lênticos, constituídos por coleções de água menos corrente, os lagos, as lagoas e as valas de drenagem, descritos em SouzA et al. (2006a).

Foi utilizado um receptor do sistema GPS, que forneceu a localização precisa dos locais de coleta. As coletas foram realizadas com uma rede de mão (puçá), confeccionada com nylon $(50 \mathrm{~cm}$ de largura, $40 \mathrm{~cm}$ de altura, $30 \mathrm{~cm}$ de abertura e $1 \mathrm{~mm}^{2}$ de malha) e adaptada a um cabo de madeira de $1,5 \mathrm{~m}$ de comprimento. $\mathrm{O}$ esforço amostral em cada um dos habitats selecionados foi de 30 minutos, por varredura com transecto em cerca de dez metros de extensão (Souza et al., 2006a). Foram georreferenciadas ao todo 147 localidades do município (SouzA et al., 2006b), algumas delas escolhidas aleatoriamente. Os moluscos foram capturados semanalmente (dois dias de coleta) e em cada uma das localidades foram realizadas duas coletas ao longo do período de estudo (uma na estação anual de seca e outra na de chuva).

O material coletado foi acondicionado em pequenas caixas de papelão, isopor ou plástico contendo camadas de papel absorvente umedecido. As caixas foram etiquetadas e transportadas para o Laboratório de Taxonomia e Biologia de Invertebrados do Departamento de Parasitologia, do Instituto de Ciências Biológicas da Universidade Federal de Minas Gerais (ICB/UFMG).

No laboratório os moluscos foram quantificados, observados macroscopicamente e, a seguir, colocados individualmente em recipientes de vidro "snap cap" contendo $5 \mathrm{ml}$ de água isenta de cloro e deixados durante a noite para exame na manhã seguinte. Após o primeiro exame, em estereomicroscópio binocular em aumento de 8 a $20 \mathrm{X}$, os exemplares foram expostos à iluminação artificial direta durante duas horas e, em seguida, reexaminados (Ruzz, 1952a).

De cada lote de moluscos capturados, $10 \%$ dos exemplares foram sacrificados em água a $70^{\circ} \mathrm{C}$. 
As partes moles foram fixadas em líquido RaillietHenry e dissecadas sob estereomicroscópio, como recomendado por Paraense \& Deslandes (1955), com algumas modificações. Para identificação das espécies foram considerados parâmetros conquiliológicos e de morfologia interna (MALEK, 1962; PAHO, 1968; Paraense, 1972, 1975).

Foram obtidos os índices cercáricos globais (ICG), que representam a infecção por cercárias ou formas larvárias de trematódeos registradas em determinada espécie de molusco e os índices cercáricos específicos (ICE), que representam a infecção por determinada larva de trematódeo encontrada em determinada espécie de molusco (Ruiz, 1952d).

A caracterização das cercárias foi realizada com e sem auxílio de corantes em exemplares vivos e mortos. Para a coloração in vivo, uma gota de solução aquosa a $0,05 \%$ de vermelho neutro ou azul de metileno foi colocada sobre a suspensão cercariana (PORTER, 1938; Ruiz, 1952a; Frandsen \& Christensen, 1984). Para o estudo de larvas mortas algumas foram coradas com solução de Lugol e outras foram fixadas em formalina a $10 \%$, coradas com carmim acético, carmim clorídrico ou carmim bórax, desidratadas em série alcoólica crescente, clarificadas em creosoto de Faia e montadas em bálsamo do Canadá (Ruiz, 1952a,b; Veitenheimer-Mendes, 1982; Melo, 2008).

As larvas foram desenhadas em microscópico binocular adaptado com câmara-clara. Utilizou-se um mínimo de 10 cercárias para mensuração, que foi registrada em micrômetros, e o valor apresentado se refere à média. Os desenhos obtidos foram comparados com as descrições e chaves de identificação (LuTZ, 1933; Ruiz, 1943, 1952a,c,d, 1953, 1957; MaLeK, 1962; Schell, 1970; Veitenheimer-Mendes, 1982; Frandsen \& Christensen, 1984). Foi usado o sistema alfa-numérico para designação das larvas e o material estudado encontra-se depositado na coleção taxonômica do Departamento de Parasitologia da UFMG (DPIC).

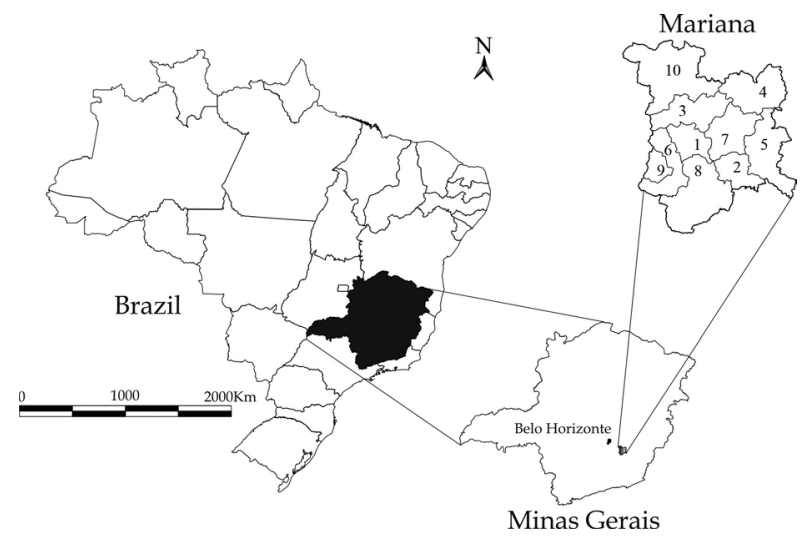

Fig. 1. Mapa do município de Mariana, Minas Gerais, Brasil, com a sede e os respectivos distritos: 1, Bandeirantes; 2, Cachoeira do Brumado; 3, Camargos; 4, Cláudio Manuel; 5, Furquim; 6, Mariana (sede do município); 7, Monsenhor Horta; 8, Padre Viegas; 9, Passagem de Mariana; 10, Santa Rita Durão.

\section{RESULTADOS}

Foram registrados moluscos em 86 localidades das 147 estudadas em todos os distritos e a sede do município de Mariana. Entre os espécimes coletados, o gênero Physa Draparnaud, 1801 apresentou o maior número de exemplares (12.092) seguido por Biomphalaria Preston, 1910 com 11.147 exemplares e cuja única espécie foi B. glabrata. Ainda, foram coletados 24 exemplares de Lymnaea columella, dois de Melanoides tuberculata, quatro de Drepanotrema anatinum (d'Orbigny, 1835) e dois de D. lucidum, relatados anteriormente por SouzA et al. (2006).

Dos 12.092 espécimes de $P$. marmorata, somente um exemplar (ICG de 0,01\%) da Barroca, distrito de Cachoeira do Brumado, apresentou uma xifidocercária (SM3, abaixo caracterizada), enquanto que dos 11.147 exemplares de B. glabrata coletados foram obtidos 134 (ICG de 2,19\%) moluscos positivos para os seguintes tipos larvais: cercária de $S$. mansoni BM1, verificada em 111 espécimes, estrigeocercária BM2, em 07, equinóstoma SM1, encontrada em dois exemplares e ocelífera BM3, xifidiocercária SM2, gimnocéfala SM4 e gimnocéfala SM5, observadas em somente um exemplar. Destas, a xifidiocercária SM2 e a cercária de cauda bifurcada BM1, também denominada Cercaria blanchardi ou larva de S. mansoni, não foram aqui caracterizadas por já serem conhecidas.

Entre os trematódeos observou-se que as larvas de cauda bifurcada emergiram após fotoestimulação, enquanto as de cauda simples emergiram à noite.

Cercária equinóstoma SM1 (Fig. 2). Larva emergente à noite. Molusco hospedeiro: B. glabrata Índice cercárico específico: 0,03\%.

Distrito de Cachoeira do Brumado, Cachoeira

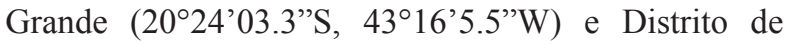
Santa Rita Durão, Bento Rodrigues (20¹4'2.6”'S, $\left.43^{\circ} 25^{\prime} 32.3^{\prime \prime} \mathrm{W}\right)$.

Medidas. Corpo: comprimento 274,5 (258,4 $283,9)$, largura $102,0(83,3-122,4)$; cauda: comprimento $508,0(493,0-542,3)$, largura $33,7(27,2-44,2)$; ventosa oral: comprimento $46,5(42,5-56,1)$, largura $43,2(42,5$ - 44,2); ventosa ventral: comprimento 53,4 $(45,9-59,5)$, largura 37,4 (34,0 - 40,8); relação corpo/cauda: 0,54: 1 .

Descrição. Corpo alongado com a extremidade anterior rodeada de espinhos, típicos das cercárias equinóstomas, que formam o colar cefálico (o número de espinhos não foi determinado usando-se as técnicas de coloração apresentadas na metodologia). Conjunto de três espinhos lateralmente entre a ventosa oral e a faringe. Ventosa oral subterminal e ventosa ventral na região subequatorial do corpo, esta um pouco maior que a ventosa oral. Pré-faringe longa e faringe musculosa, alongada. Esôfago curto, comunica-se com os dois cecos logo após a faringe. Cecos desenvolvidos, prolongados até a extremidade posterior do corpo, terminando em fundo cego, próximo à vesícula excretora. Região abaixo 
e posterior ao acetábulo com dois grupos de células que provavelmente constituem os primórdios genitais. Sistema excretor formado por dois canais excretores que percorrem as margens laterais do corpo. Estes partem da vesícula excretora, terminando próximo à ventosa oral. Entre a faringe e a ventosa ventral os canais excretores são preenchidos por inúmeras concreções circulares. Vesícula excretora com paredes espessas. Cauda longa e afilada na extremidade posterior, contendo inúmeras células em toda a extensão. Estendendo-se por toda a cauda, em sua porção mediana, observa-se o canal do sistema excretor.

Xifidiocercária SM2. Larva emergente à noite.
Molusco hospedeiro: B. glabrata. Índice cercárico específico: $0,02 \%$.

Distrito de Cláudio Manuel, Cana do Reino I $\left(20^{\circ} 14^{\prime} 2.6^{\prime \prime} \mathrm{S}, 43^{\circ} 25^{\prime} 32.3^{\prime \prime} \mathrm{W}\right)$ e Distrito de Furquim,

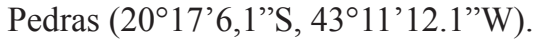

Xifidiocercária SM3 (Fig. 3). Larva emergente à noite. Molusco hospedeiro: $P$. marmorata. Índice cercárico específico: 0,01\%.

Distrito de Cachoeira do Brumado, Barroca (20²6’25.8”'S, 4314'16.5”'W).

Medidas. Corpo: comprimento 185,0 (173,4 207,4), largura 136,0 (117,3 - 144,5); cauda: comprimento $366,2(348,5-382,5)$, largura $33,0(30,6-35,7)$; ventosa

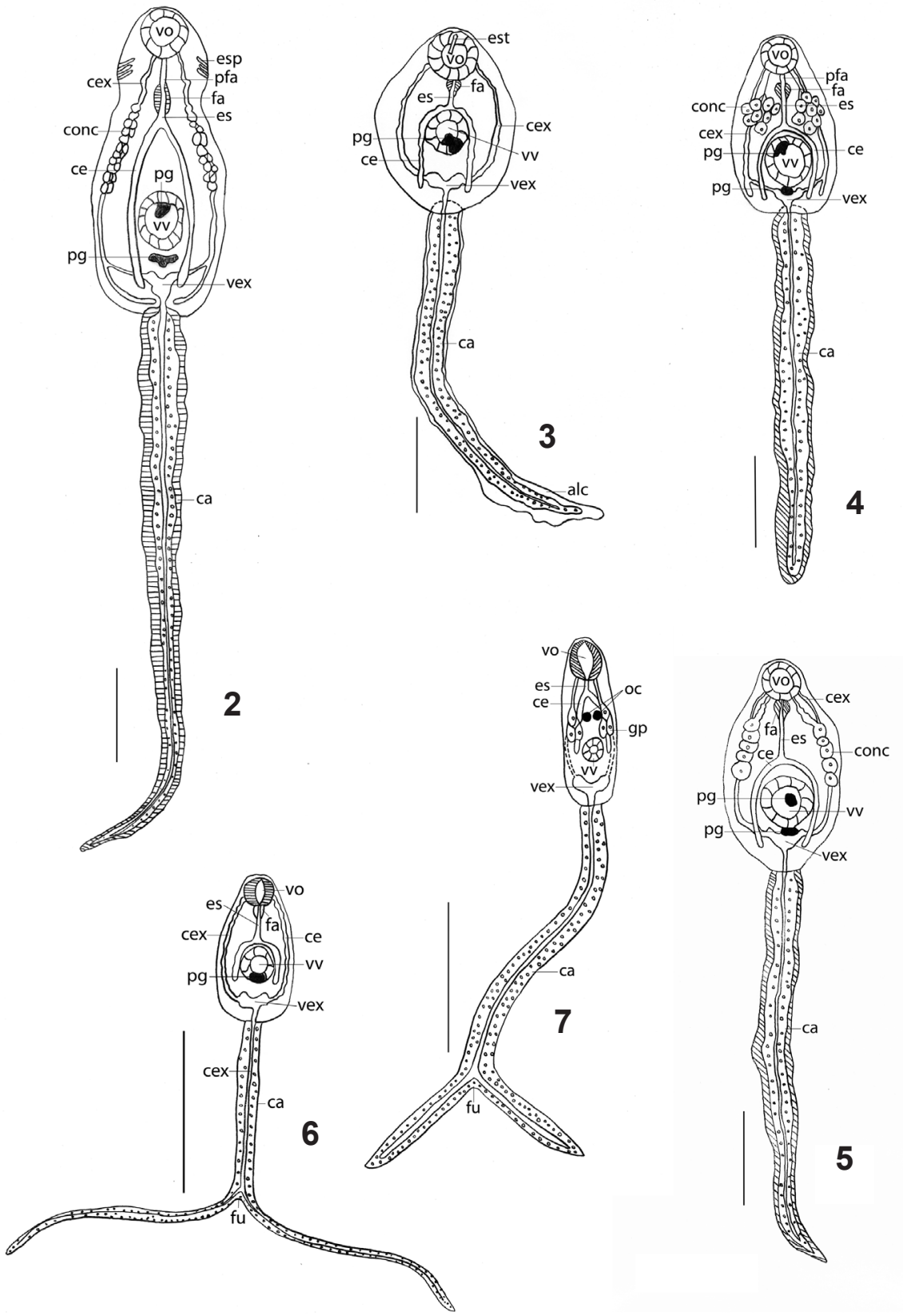

Figs 2-7. Cercárias de cauda simples e bifurcada registradas em Mariana, Minas Gerais, Brasil: 2, equinóstoma SM1; 3, xifidiocercária SM3; 4, gimnocéfala SM4; 5, gimnocéfala SM5; 6, estrigeocercária BM2; 7, ocelífera BM3 (alc, aleta caudal; ca, cauda; ce, ceco; cex, canal excretor; conc, concreções; es, esôfago; esp, espinhos; est, estilete; fa, faringe; fu, furca; gp, glândula de penetração; oc, ocelos; pfa, pré-faringe; pg, primórdio genital; vex, vesícula excretora; vo, ventosa oral; vv, ventosa ventral). Barra: 0,10 mm. 
oral: comprimento 50,0 (47,6 - 52,7), largura 47,9 (45,9 - 51,0); ventosa ventral: comprimento 41,8 (39,1 44,2), largura 41,5 (37,4 - 44,2); relação corpo/cauda: $0,51: 1$.

Descrição. Espinho situado na extremidade anterior do corpo, na região da ventosa oral, ultrapassa mais da metade desta. Corpo curto, largo, oval. Ventosa oral esférica e subterminal. Ventosa ventral um pouco menor que a ventosa oral, situada na região mediana do corpo, sobreposta ao primórdio genital que é evidente. Pré-faringe ausente ou reduzida, seguida de faringe musculosa, piriforme. Esôfago curto, bifurcado anteriormente, junto à ventosa ventral. Cecos relativamente longos, ultrapassam a ventosa ventral e terminam próximo à vesícula excretora. Vesícula excretora com furcas excretoras largas, bifurcadas abaixo da ventosa ventral. As furcas excretoras recebem os canais excretores que percorrem lateralmente o corpo da cercária até sua extremidade anterior, próximo à ventosa oral. Cauda afilada e mais longa que o corpo, apresentando, além de inúmeras células em toda a extensão, uma expansão lateral (aleta caudal) fina e delgada na região posterior. Canal do sistema excretor estende-se por toda a cauda, em sua porção mediana.

Gimnocéfala SM4 (Fig. 4). Larva emergente à noite. Molusco hospedeiro: B. glabrata. Índice cercárico específico: 0,02\%.

Distrito: Bandeirantes, Sítio Olegário (20²1'19.3”S, 4322'04.7' W).

Medidas. Corpo: comprimento 180,7 (170,0 $195,5)$, largura $92,5(73,1-100,3)$; cauda: comprimento $371,8(345,1-394,4)$, largura $37,4(28,9-44,2)$; ventosa oral: comprimento $39,3(34,0-42,5)$, largura $35,5(34,0$ - 37,4); ventosa ventral: comprimento 50,3 (42,5 - 52,7), largura 49,5 (42,5 - 52,7); relação corpo/cauda: 0,49: 1.

Descrição. Corpo oval, achatado. Ventosa oral subterminal, menor que a ventosa ventral. Pré-faringe curta, seguida de faringe musculosa e alongada. Esôfago relativamente longo, bifurcado na região mediana do corpo, anteriormente e próximo à ventosa ventral. Cecos longos, ultrapassam a ventosa ventral e terminam próximo à extremidade do corpo da cercária. Ventosa ventral maior que a oral, situada logo após a linha equatorial do corpo. Primórdio genital bem desenvolvido, situado abaixo e posterior à ventosa ventral. Vesícula excretora desenvolvida, com os canais excretores que percorrem os campos laterais do corpo e alcançam a ventosa oral. Nas áreas laterais, situadas entre a ventosa ventral e a faringe, são observados dois grupos de concreções esféricas, um de cada lado e parecem estar acumulados dentro de alargamentos dos canais excretores laterais. Cauda longa, envolvida por uma fina membrana transparente. Em sua porção mediana, observa-se o canal do sistema excretor e em toda a sua extensão são observadas numerosas células.

Gimnocéfala SM5 (Fig. 5). Larva emergente à noite. Molusco hospedeiro: B. glabrata. Índice cercárico específico: 0,02\%.

Distrito: Bandeirantes, Olaria $\left(20^{\circ} 10^{\prime} 42.9^{\prime \prime} \mathrm{S}\right.$, $43^{\circ} 24^{\prime} 47.7^{\prime} \mathrm{W}$ ).

Medidas. Corpo: comprimento 213,2 (202,3 - 226,1), largura 110,2 (102,0 - 115,6); cauda: comprimento 413,8 (404,6 - 425,0), largura 34,0 (27,2 - 42,5); ventosa oral: comprimento $37,7(34,0-40,8)$, largura 35,4 (34,0 - 37,4); ventosa ventral: comprimento $50,0(45,9$ - 51,0), largura 50,3 $(47,6$ - 52,7); relação corpo/cauda: 0,51: 1 .

Descrição. Corpo alongado, subelíptico. Préfaringe não observada. Faringe musculosa e alongada. Esôfago longo, bifurcado na região mediana do corpo, anterior à ventosa ventral. Cecos longos ultrapassam a ventosa ventral e alcançam as laterais da vesícula excretora, terminando em fundo cego. Ventosa ventral maior que a oral, situada na região subequatorial do corpo. Primórdio genital desenvolvido, situado abaixo e posterior à ventosa ventral. Vesícula excretora desenvolvida, com os canais excretores que percorrem os campos laterais do corpo e terminam próximos à ventosa oral. Dois grupos de concreções esféricas situados, um de cada lado, nas áreas laterais do corpo, entre a faringe e a vesícula excretora; tais grupos parecem estar acumulados dentro de alargamentos dos canais excretores laterais. Cauda longa, com numerosas células e extremidade afilada, envolvida por uma fina membrana transparente. Por toda a cauda, em sua porção mediana, estende-se o canal do sistema excretor.

Estrigeocercária BM2 (Fig. 6). Larva emergente, após fotoestimulação artificial. Molusco hospedeiro: $B$. glabrata. Índice cercárico específico: 0,11\%.

Distrito de Cláudio Manuel, Cana do Reino II (20¹4'31.5”S, 43¹2'6.2”'W).

Medidas. Corpo: comprimento 87,4 (85,0 - 95,5), largura 43,9 (40,8 - 45,9); cauda: comprimento 244,1 $(238,0-249,9)$, largura $11,9(10,2-13,6)$; ventosa oral: comprimento $17,7(17,0-20,4)$, largura $17,3(17,0-$ $18,7)$; ventosa ventral: comprimento $20,7(20,4-22,1)$, largura 20,7 (20,4 - 22,1); furca: comprimento 139, 4 (136,0 - 144,5); relação corpo/ corpo da cauda: 0,83: 1; relação corpo/cauda total: $0,36: 1$; relação corpo da cauda/ furca: 0,75: 1 .

Descrição. Comprimento do corpo cerca de duas vezes maior que a largura. Ventosa oral arredondada, com musculatura radial inconspícua, pouco menor que a ventosa ventral e situada na porção subterminal do corpo. Ventosa ventral esférica, um pouco acima da região equatorial do corpo. Faringe curta e estreita. Esôfago longo bifurcado antes da ventosa ventral. Cecos ultrapassam a ventosa ventral. Primórdio genital situado na região subequatorial do corpo. Vesícula excretora desenvolvida, cujos canais excretores percorrem lateralmente o corpo e alcançam a extremidade anterior, próximo à ventosa oral. Cauda longifurcada, com numerosas células em sua extensão: apresenta um 
canal excretor na região mediana, que percorre toda a extensão.

Cercária ocelífera BM3 (Fig. 7). Larva emergente, após fotoestimulação artificial. Molusco hospedeiro: $B$. glabrata. Índice cercárico específico: 0,02\%.

Distrito de Santa Rita Durão, Ponte de Bento Rodrigues: (20¹4'2.6”S, 43²5'32.3'W).

Medidas. Corpo: comprimento 107,7 (102,0 $113,9)$, largura 30,6 $(27,2-34,0)$; cauda: comprimento $287,9(280,5$ - 299,2), largura 20,4 (17,0 - 23,8); ventosa oral: comprimento $26,1(25,5-27,2)$, largura 19,3 (17,0 - 20,4); ventosa ventral: comprimento 10,8 (10,2 $11,9)$, largura 14,2 (13,6 - 15,3); furca: comprimento 81,0 (68,0 - 90,1); relação corpo/corpo da cauda: 0,52: 1; relação corpo/ cauda total: $0,37: 1$; relação corpo da cauda/furca: 2,55: 1 .

Descrição. Ventosa oral oval, musculatura radial imperceptível. Ventosa ventral esférica, menor que a ventosa oral, situada na região subequatorial do corpo. Esôfago curto, bifurcado anteriormente aos ocelos. Cecos curtos terminando próximo à ventosa ventral. Faringe ausente. Glândulas de penetração saculiformes, desenvolvidas, com ductos longos, situadas na região próxima à ventosa ventral. Ocelos grandes, pigmentados, dispostos um pouco acima da região equatorial do corpo. Vesícula excretora desenvolvida. Cauda longa, relativamente larga, com numerosas células. Furca típica das cercárias brevifurcadas. Por toda a cauda em sua porção mediana, observa-se o canal do sistema excretor, que se bifurca um pouco antes do entroncamento das furcas, percorrendo a cauda até a extremidade.

\section{DISCUSSÃO}

Foram observados oito tipos de larvas, sendo caracterizadas seis novas larvas de trematódeos digenéticos, oriundos de moluscos encontrados em diversos ambientes do município de Mariana. As larvas encontradas foram organizadas em dois grupos: cercárias com cauda bifurcada (estrigeocercárias BM1 e BM2 e ocelífera BM3) e com cauda simples (equinóstoma SM1, xifidiocercárias SM2, SM3 e gimnocéfalas SM4 e SM5).

A estrigeocercária BM2, larva distoma longifurcada e faringeata, é produzida por espécies de Strigeidae e/ou Diplostomidae, parasitos intestinais de répteis, aves e mamíferos. Apesar das estruturas desta cercária serem parecidas com as de outras larvas descritas, como tamanho e aspecto da cauda semelhante a Cercaria amplicoecata descrita por RuIz (1953), ela diferencia-se das demais espécies descritas pela largura do corpo ser consideravelmente maior que a largura da cauda.

A cercária ocelífera BM3 é, de acordo com Schell (1970) e Frandsen \& Christensen (1984), uma larva distoma brevifurcada e afaringeada pertencente ao grupo Ocellata. Produzida por trematódeos,
Schistosomatidae e Spirorchiidae, parasitos de vasos sanguíneos de répteis, aves e mamíferos, sua principal característica são os ocelos presentes na região mediana do corpo. As dimensões da cercária BM3 do presente estudo assemelham-se àquelas descritas por LuTz (1934) e RuIz (1953), todavia, não foram observados espinhos na região cefálica e cerdas na cutícula caudal.

A cercária equinóstoma SM1 é gerada por trematódeos Echinostomatidae (parasitos intestinais de aves, répteis e mamíferos), cuja principal característica é o colar cefálico com espinhos que contorna toda parte dorsal do corpo. Embora este colar não tenha sido totalmente evidenciado, sua presença confere a denominação de equinóstoma. Assemelha-se muito a Cercaria macrogranulosa descrita por RuIz (1952c), obtida em B. glabrata de Minas Gerais e às cercárias equinóstoma 2 (VeItenheIMER-MENDES, 1982) de $B$. peregrina (d'Orbigny 1835) do Rio Grande do Sul e S2 (BoAventura et al., 2002), presentes em P. marmorata do Rio de Janeiro.

As xifidiocercárias são reconhecidas pelo estilete na região da ventosa oral. Destas, a xifidiocercária SM3 é produzida por espécies de Macroderoididae (parasitos intestinais de peixes, anfíbios e répteis) e Haplometridae (parasitos pulmonares de anfíbios). Devido à presença da aleta caudal, foi alocada no grupo ornata (SCHELL, 1970; Ostrowski dE NuÑEZ, 1974; FrAndSEN \& Christensen, 1984). O tipo larval SM3 diferencia-se da xifidiocercária 1 (Veitenheimer-Mendes, 1982), pela cauda maior e por não apresentar os longos pelos sensitivos. O comprimento da cauda, a presença da aleta caudal, além da ausência do órgão vírgula é o que a diferencia das xifidiocercárias SM2. Ambas cercárias aqui caracterizadas são diferentes das encontradas por Carvalho et al. (2001a,b) em São Paulo.

As cercárias gimnocéfalas são produzidas por espécies de Fasciolidae (primariamente parasitos do intestino, fígado e vias biliares de mamíferos herbívoros e aves). PorTer (1938) descreveu cercárias gimnocéfalas emergentes de várias espécies de moluscos. Neste estudo, as cercárias gimnocéfalas SM4 e SM5 diferenciam-se daquelas abordadas por PorTer (1938) pelas medidas do corpo, cauda e ventosas. Diferem também da cercária de Fasciola hepatica (Linnaeus, 1758) pelas dimensões do corpo, da cauda e pelo hospedeiro invertebrado, $B$. glabrata. As duas espécies diferenciam-se entre si pela localização da faringe e pela disposição das concreções circulares.

Entre as gimnocéfalas encontradas em Mariana, SM5 apresenta faringe próxima à ventosa oral, sem préfaringe, e as concreções circulares dispostas por quase toda a face lateral do corpo, ao passo que a gimnocéfala SM4 apresenta a faringe afastada da ventosa oral, préfaringe presente e as concreções circulares próximas, situadas na região mediana do corpo.

Considerado a enorme variedade de larvas de trematódeos existentes, são necessários estudos mais 
aprofundados visando a elucidação dos ciclos evolutivos que poderão permitir a completa identificação das larvas relatadas neste trabalho, suas interações com os hospedeiros intermediários e os ciclos biológicos existentes.

Agradecimentos. Ao Sr. Aírton Lobo, pela assistência técnica e auxílio na preparação das lâminas contendo os trematódeos. Ao Prof. Roney Elias da Silva, pelo auxílio na caracterização das larvas de trematódeos. À Prof ${ }^{\text {a. }}$ Dr $^{\text {a. }}$ Karina Carvalho Mancini, pelo especial auxílio na elaboração final das figuras.

\section{REFERÊNCIAS BIBLIOGRÁFICAS}

Boaventura, M. F.; Fernandez, M. A.; Thiengo, S. C.; Silva, R. E. \& MeLo, A. L. 2002. Formas larvais de Trematoda provenientes de gastrópodes límnicos da microrregião Rio de Janeiro, sudeste do Brasil. Lundiana 3:79-80.

Bogéa, T.; Cordeiro, F. M. \& Gouveia, J. S. 2005. Melanoides tuberculatus (Gastropoda: Thiaridae) as intermediate host of Heterophyidae (Trematoda: Digenea) in Rio de Janeiro metropolitan area, Brazil. Revista do Instituto de Medicina Tropical de São Paulo 47:87-90.

Carvalho, G. A.; Ueta, M. T. \& Andrade, C. F. S. 2001a. Búsqueda de xifidiocercarias (Trematoda) em moluscos de agua dulce recolectados em nueve municipios del Estado de São Paulo, Brasil. Boletín Chileno de Parasitologia 56: 3-9.

.2001b. Estudios morfométricos y biológicos de xifidiocercarias (Trematoda) provenientes de la infección natural de Lymnaea columella Say, 1817 (Basommatophora, Lymaenidae) y Biomphalaria tenagophila Orbigny, 1835 (Basommatophora, Planorbidae) recolectados en Miracatu, Estado São Paulo, Brasil. Boletín Chileno de Parasitologia 57:59-65.

CPRM - Centro de Pesquisa em Recursos Minerais. 1993. Levantamentos Geológicos Básicos do Brasil, Mariana - Folha SF. 23- XB - 1. Estado de Minas Gerais. Escala 1: 100.000. Brasília, DNPM/CPRM. 196p.

Dias, M. L. G. G.; Eiras, J. C.; Machado, M. H.; Souza, G. T. R. \& Pavanelli, G. C. 2002. Cercariae infection in planorbidae molluscs from the floodplain of the high Paraná river, Brasil. Arquivos do Instituto Biológico de São Paulo 69:27-31

Espíndola, K. S.; Machado, M. M. \& Hofmann, P. R. P. 1992. Natural and experimental infection of planorbids from the island of Santa Catarina (Brazil). Revista do Instituto de Medicina Tropical de São Paulo 34:289-294.

Frandsen, F. \& Christensen, N. O. 1984. An introductory guide to the identification of cercariae from African freshwater snails with special reference to cercariae of trematode species of medical and veterinary importance. Acta Tropical 41:181-202.

IBGE - Instituto Brasileiro de Geografia e Estatística. 2000. Censo 2000. Disponível em: <www.ibge.gov.br/cidadesat/default.php>. Acesso em: 24.10.2003.

LuTZ, A. 1917. Observações sobre a evolução do Schistosoma mansoni ( $2^{\mathrm{a}}$ nota prévia). Brasil Médico 31:81-82, 89-90.

1918. Caramujos de água doce do gênero Planorbis, observados no Brasil. Memórias do Instituto Oswaldo Cruz 10(1):45-82.

1919. O Schistosoma mansoni e a schistosomatose segundo observações feitas no Brasil. Memórias do Instituto Oswaldo Cruz 14:95-103.

1922. Introdução ao estudo da evolução dos endotrematodes brasileiros. Memórias do Instituto Oswaldo Cruz 24:95-103.

. 1924. Estudos sobre a evolução dos endotrematodes brazileiros. Parte especial: 1. Echinostomidae. Memórias do Instituto Oswaldo Cruz 27:55-73.

1931. Contribuição ao Conhecimento da Ontogenia das Strigeidas. Memórias do Instituto Oswaldo Cruz 25(4):333-342. . 1933. Notas sobre Dicranocercárias brasileiras. Memórias do Instituto Oswaldo Cruz 27:349-402.

.1934. Outro grupo de Trematodes nascendo de Dicranocercárias e outro caso de espécies com coecos abrindo para fora. Memórias do Instituto Oswaldo Cruz 29:229-238.

Machado, S. M. P.; Cordeiro, N. S.; Artigas, P. T. \& Magalhães, L. A. 1987. Algumas considerações sobre cercárias naturalmente encontradas em Biomphalaria tenagophila (Orbigny, 1835), capturadas em Louveira, SP. Memória do Instituto Butantan 49:79-86.

MaLeK, E. A. 1962. Laboratory Guide and Notes for Medical Malacology. Minneapolis, Burgess. 154p.

MeLo, A. L. 2008. Caracterização de larvas de trematódeos emergentes de moluscos dulciaquícolas. In: Amaral, R. S.; Thiengo, S. C. \& PIERI, O. S. eds. Vigilância e controle de moluscos de importância epidemiológica: diretrizes técnicas: Programa de Vigilância e Controle da Esquistossomose (PCE). Brasília, Ministério da Saúde. p. 71-80. Série A. Normas e Manuais Técnicos.

Melo, A. L. \& Pereira, L. H. 1985. On the finding of Biomphalaria tenagophila naturally infected with Schistosoma mansoni in the state of Minas Gerais, Brasil. Revista do Instituto de Medicina Tropical de São Paulo 27:99-101.

Moura, S. A. L. 1945. Schistosomose mansoni autóctone em Santos. Revista do Instituto Adolpho Lutz 5:279-311.

Ostrowski de Nuñez, M. 1974. Fauna de agua dulce de la República Argentina. III. Neotrópica 20:67-72.

PAно - Pan American Health Organization. 1968. A guide for the identification of the snail intermediate hosts of Schistosomiasis in the Americas. Washington, World Health Organization. Scientific Publication n. 168. 129p.

Paraense, W. L. 1951. Observações adicionais sobre o sexo do Schistosoma mansoni nas infestações por cercárias de um único sexo. Memórias do Instituto Oswaldo Cruz 47:535-556.

. 1972. Fauna planorbídica do Brasil. In: LaCAZ, C. S.; Baruzzi, R. G. \& SiqueIRA JR., W. eds. Introdução à geografia médica do Brasil. São Paulo, Edgard Blücher, EDUSP. p. 213-239.

1975. Estado atual da sistemática dos planorbídeos brasileiros. Arquivos do Museu Nacional do Rio de Janeiro 55:105-127.

Paraense, W. L. \& Deslandes, N. 1955. Observations on the morphology of Australorbis nigricans. Memórias do Instituto Oswaldo Cruz 53:121-124.

Pinto, H. A. \& Melo, A. L. 2010a. Melanoides tuberculata (Mollusca: Thiaridae) as an intermediate host of Centrocestus formosanus (Trematoda: Heterophyidae) in Brazil. Revista do Instituto de Medicina Tropical de São Paulo 51(4):207-210

2010b. Melanoides tuberculata as intermediate host of Philophthalmus gralli in Brazil. Revista do Instituto de Medicina Tropical de São Paulo 51(6):323-327.

. 2011. A checklist of trematodes (Platyhelminthes) transmitted by Melanoides tuberculata (Mollusca: Thiaridae). Zootaxa 2799:15-28.

PiraJÁ DA Silva, M. A. 1912. Cercaire brésilienne (Cercaria blanchardi) à queue bifurqueé. Archives de Parasitologie 15:398.

Porter, A. 1938. The larval trematoda found in certain South African Mollusca with special reference to schistosomiasis (Bilharziasis). Publications of the South African Institute for Medical Research 8(42):1-492.

RuIz, J. M. 1943. Contribuição ao estudo das formas larvárias de trematódeos brasileiros. Anais da Faculdade de Farmácia e Odontologia da Universidade de São Paulo 3:105-112.

1952a. Noções técnicas aplicadas à epidemiologia da Schistosomose. 1. Captura de moluscos. Pesquisa e reconhecimento de cercárias. Anais da Faculdade de Farmácia e Odontologia da Universidade de São Paulo 10:41-62.

1952b. Contribuição ao estudo das formas larvárias de trematódeos brasileiros. 2. Fauna de Santos, Estado de São Paulo. Memórias do Instituto Butantan 24:17-36.

1952c. Contribuição ao estudo das formas larvárias de trematódeos brasileiros. 3. Fauna de Belo Horizonte e Jaboticatubas. Estado de Minas Gerais. Memórias do Instituto Butantan 24:45-62.

1952d. Índices cercáricos específicos do Schistosoma mansoni verificados em Neves e Mariana, Estado de Minas Gerais. Memórias do Instituto Butantan 24:63-68.

1953. Contribuição ao estudo das formas larvárias de trematódeos brasileiros. 5. Descrição das três furcocercárias que ocorrem em planorbídeos hospedeiros do Schistosoma mansoni. Memórias do Instituto Butantan 25:77-89.

1957. Contribuição ao conhecimento dos planorbídeos da cidade de São Paulo. Revista Brasileira de Malariologia e Doenças Tropicais 9:57-65.

Schell, C. S. 1970. How to know the trematodes. Dubuque, Company Publishers. 355p. 
Souza, C. P.; Lima, L. C.; Zannotti-Passos, L. K.; Ferreira, S. S.; Guimarães, C. T.; Vieira, L. B. F. \& Mariani JunioR, R. J. 1998. Moluscos límnicos da Microrregião de Belo Horizonte, Minas Gerais, com ênfase nos vetores de parasitoses. Revista da Sociedade Brasileira de Medicina Tropical 31:449-456.

Souza, M. A. A.; Souza, L. A.; Machado-Coelho, G. L. L. \& Melo, A. L. 2006a. Levantamento malacológico e mapeamento das áreas de risco para transmissão da esquistossomose mansoni no município de Mariana, MG. Revista de Ciências Médicas e Biológicas 5:132-139.

Souza, M. A. A.; Melo, A. L. \& Vianna, G. J. C. 2006a. Heterópteros aquáticos oriundos do município de Mariana, MG. Neotropical Entomology 35(6):803-810.

Strahler, A. N. 1963. The Köppen climate classification system. In: Strahler, A. N. ed. Physical Geography. New York, John Willey. p. 185-188.

Thiengo, S. C.; Fernandez, M. A.; Boaventura, M. F. \& Stortti, M. A. 1998. A survey of freshwater gastropods in the Microrregião Serrana of the state of Rio de Janeiro, Brazil. Memórias do Instituto Oswaldo Cruz 93(1):233-234.
Thiengo, S. C.; Fernandez, M. A.; Boaventura, M. F.; Grault, C. E.; Silva, H. F. R.; Mattos, A. C. \& Santos, S. B. 2001. Freshwater snails and schistosomiasis mansoni in the state of Rio de Janeiro, Brazil: I- Metropolitan Mesoregion. Memórias do Instituto Oswaldo Cruz 96(1):177-184

Veitenheimer-Mendes, I. L. 1981. Cercárias em Biomphalaria tenagophila (Orbigny, 1835) (Mollusca, Planorbidae) de Guaíba, Rio Grande do Sul, Brasil. Iheringia, Série Zoologia (60):3-12.

. 1982. Cercárias em moluscos planorbídeos de Camaquã, Rio Grande do Sul, Brasil. Revista Brasileira de Biologia 42:545-551.

Veitenheimer-Mendes, I. L. \& Almeida-Caon, J. E. M. 1989. Drepanotrema kermatoides (d' Orbigny, 1835) (Mollusca, Planorbidae), hospedeiro de um paranfistomídeo (Trematoda), no Rio Grande do Sul, Brasil. Memórias do Instituto Oswaldo Cruz 84:107-111.

Veitenheimer-Mendes, I. L.; Ohlweiler, F. P. \& Blum, C. 1995. Gastrópodes límnicos (Mollusca), hospedeiros intermediários de trematódeos (Platyhelminthes) em Porto Alegre e Viamão, Rio Grande do Sul. Biociências 3(1):73-84. 